\title{
Pemberdayaan Perempuan Melalui Pelatihan Pijat Nifas Bagi Kader di Desa Babakan Kecamatan Ciparay Kabupaten Bandung
}

\author{
OD Sariningsih \\ Program Studi D3 Kebidanan Sekolah Tinggi Ilmu Kesehatan Immanuel Bandung, \\ odsari@yahoo.co.id
}

\begin{abstract}
Abstrak
Salah satu cara efektif dalam meningkatkan produktifitas Indonesia adalah melalui pemberdayaan perempuan. Negara perlu melakukan investasi terhadap perempuan dengan menjamin kesehatannya secara menyeluruh. Pemberdayaan perempuan tidak serta merta menjadi tanggung jawab pemerintah. Peran masyarakat sangat dibutuhkan untuk mendukung program-program dari berbagai sektor. Kesehatan perempuan, dapat dilakukan bersinergi antara pemerintah dan masyarakat. Sekolah Tinggi Ilmu Kesehatan Immanuel melalui Program Studi D3 Kebidanan mengambil peluang dalam rangka pengabdian kepada masyarakat khususnya para perempuan. Daerah yang disasar adalah Desa Babakan di Kecamatan Ciparay Kabupaten Bandung. Program-program Kesehatan Ibu dan Anak dan Kesehatan Reproduksi, menjadi salah satu yang diperhatikan. Data menunjukan jumlah kader 28 orang dengan kompetensi yang dimiliki adalah pengelolaan posyandu 5 meja, pendampingan perempuan yang memerlukan rujukan kesehatan dan kegiatan lainnya seperti olah raga. Berdasarkan latar belakang maka dilakukanlah pengabdian kepada masyarakat melalui topik "Pemberdayaan Perempuan Melalui Pelatihan Pijat Nifas Bagi Kader di Desa Babakan Kecamatan Ciparay Kabupaten Bandung". Tujuan; tercapainya pemberdayaan perempuan melalui kemampuan kader untuk melakukan pijat nifas. Manfaat; pengetahuan, pemahaman dan kemampuan kader dalam hal pijat nifas serta kemampuan untuk menambah pemasukan ekonomi. Metode; Analisis situasi, kajian/survey awal, kajian potensi kader posyandu, perijinan, penyusunan materi , implementasi, evaluasi, perumusan laporan kegiatan dan publikasi. Hasil; Pengetahuan kader tentang pijat nifas sebagian besar berpengetahuan cukup 14 orang, berpengetahuan baik 10 orang dan berpengetahuan kurang 2 orang. Pemahaman kader tentang pijat nifas sebagian besar berpengetahuan cukup 14 orang, berpengetahuan baik 12 orang dan berpengetahuan kurang 2 orang. Kemampuan kader setelah mengikuti pelatihan pijat nifas dengan kemampuan baik 26 orang, kemampuan cukup 2 orang. Sebagai tindak lanjut dari pelatihan ini, maka pelatih berkolaborasi bersama petugas kesehatan dan pemerintahan setempat untuk melakukan pemantauan selanjutnya. Simpulan; pemberdayaan perempuan melalui pelatihan pijat nifas bagi kader bahwa sebagian pengetahuan dan pemahaman kader tentang pijat nifas adalah cukup. Kemampuan kader dalam mengimplemetasikan pijat nifas adalah baik. Manfaat penyerta yang bisa dimanfaatkan bagi kader adalah menambah pemasukan ekonomi. Rekomendasi pelatihan ini diperlukan pendampingan dan pemantauan petugas kesehatan dan pemerintah setempat untuk mengembangkan terus potensi kader dalam rangka pemberdayaan perempuan. Pelatihan pijat nifas ini terbatas, sehingga diperlukan pelatihan-pelatihan lanjutan atau topik lainnya untuk lebih
\end{abstract}


Jurnal Pengabdian Kepada Masyarakat

memampukan pemberdayaan perempuan. Ucapan terimakasih kepada Dinas Kesehatan Kabupaten Bandung, Puskesmas Pakutandang Ciparay Kabupaten Bandung dan Kepala Desa Babakan Kecamatan Ciparay Kabupaten Bandung beserta jajarannya.

Kata kunci :pemberdayaan perempuan, kader,pelatihan, pijat nifas, ekonomi

\begin{abstract}
One effective way to increase Indonesia's productivity is through empowering women. The state needs to invest in women by ensuring their overall health. Women's empowerment is not necessarily the responsibility of the government. The community role is very much needed to support programs from various sectors. Women's health, can be carried out in synergy between the government and the community. Immanuel's Health Sciences High School through the Midwifery D3 Study Program took the opportunity in the context of community service, especially for women. The targeted area is Babakan Village in Ciparay District, Bandung Regency. Maternal and Child Health and Reproductive Health programs are considered. Data shows the number of cadres of 28 people with the competencies they have is the management of 5 table posyandu, mentoring women who need health referrals and other activities such as sports. Based on the background, community service was carried out through the topic "Empowering Women through Postpartum Massage Training for Cadres in Babakan Village, Ciparay District, Bandung Regency". Aim; the achievement of women's empowerment through the ability of cadres to carry out puerperal massage. Benefits; knowledge, understanding and ability of cadres in postpartum massage as well as the ability to increase economic income. Method; Situation analysis, preliminary studies / surveys, studies of Posyandu cadre potential, licensing, material preparation, implementation, evaluation, formulation of activity reports and publications. Results; The knowledge of cadres about postpartum massage was mostly knowledgeable with 14 people, knowledgeable, 10 people and knowledgeable with less than 2 people. Most of the cadres' understanding of postpartum massage was knowledgeable with 14 people, knowledgeable, 12 people and knowledgeable with less than 2 people. The ability of cadres after participating in postpartum massage training with good ability of 26 people, sufficient ability of 2 people. As a follow up to this training, the trainers collaborate with health officials and local government to carry out further monitoring. Conclusion; empowering women through parturition massage training for cadres that some cadres' knowledge and understanding of postpartum massage is sufficient. The ability of cadres in implementing puerperal massage is good. The accompanying benefit that can be utilized by cadres is to increase economic income. This training recommendation requires assistance and monitoring of health workers and the local government to continuously develop potential cadres in the context of empowering women. This postpartum massage training is limited, so further training or other topics are needed to enable women's empowerment. Thank you to the Bandung District Health Office, Ciparay District Health Center, Bandung Regency, and the Head of the Babakan Village, Ciparay District, Bandung Regency and its staff.
\end{abstract}

Keywords: women's empowerment, cadres, training, postpartum massage, economy

\title{
Pendahuluan
}


Salah satu cara efektif dalam meningkatkan produktifitas Indonesia adalah melalui pemberdayaan perempuan. Pembangunan dan pemberdayaan perempuan harus dimulai sejak dalam kandungan. Negara perlu melakukan investasi terhadap perempuan dengan menjamin kesehatan perempuan secara menyeluruh.

Pemberdayaan perempuan tidak serta merta menjadi tanggung jawab pemerintah. Peran masyarakat sangat dibutuhkan untuk mendukung program-program dari berbagai sektor. Kesehatan perempuan, dapat dilakukan bersinergi antara pemerintah dan masyarakat.

Sekolah Tingi Ilmu Kesehatan Immanuel melalui Program Studi D3 Kebidanan mengambil peluang dalam rangka pengabdian kepada masyarakat khususnya para perempuan. Program-program Kesehatan Ibu dan Anak, Kesehatan Reproduksi, menjadi salah satu yang diperhatikan. Implementasi yang dilakukan adalah terjun ke masyarakat melalui beberapa langkah. Daerah yang disasar adalah satu desa yang berada di Kabupaten Bandung Selatan. Langkah awal dengan melakukan analisis situasi untuk mengetahui jumlah kader posyandu dan kompetensinya. Data menunjukan jumlah kader 28 orang dengan kompetensi yang dimiliki adalah pengelolaan posyandu 5 meja, pendampingan perempuan yang memerlukan rujukan kesehatan dan kegiatan lainnya seperti olah raga. Berdasarkan latar belakang diatas maka dilakukanlah pengabdian kepada masyarakat melalui topik "Pemberdayaan Perempuan Melalui Pelatihan Pijat Nifas Bagi Kader di Desa Babakan Kecamatan Ciparay Kabupaten Bandung".

Tujuan

Tercapainya pemberdayaan perempuan melalui kemampuan kader untuk melakukan pijat nifas.

Manfaat

1. Pengetahuan kader tentang manfat pijat nifas

2. Pemahaman kader tentang manfaat pijat nifas

3. Kemampuan kader melakukan pijat nifas

4. Kemampuan kader untuk menambah pemasukan ekonomi Kajian Pustaka

1. Kader dalam pelatihan ini adalah kader yang mengelola posyandu. Kader adalah warga masyarakat setempat yang dipilih dan ditinjau oleh masyarakat dan dapat bekerja secara sukarela mengelola posyandu.(Zulkifli,2003)

Kader aktif adalah kader yang selalu melaksanakan kegiatan posyandu dan selalu menjalankan tugas dan perannya sebagai kader Kader tidak aktif adalah kader yang tidak melaksanakan tugas dan perannya sebagai kader posyandu serta tidak rutin mengikuti kegiatan posyandu (Departemen Kesehatan RI,2006) Syarat Menjadi Kader Posyandu

a. Dapat membaca dan menulis

b. Berjiwa sosial dan mau bekerja secara relawan

c. Mengetahui adat istiadat serta kebiasaan masyarakat

d. Mempunyai waktu yang cukup

e. Bertempat tinggal di wilayah posyandu 
f. Berpenampilan ramah dan simpatik

g. Mengikuti pelatihan-pelatihan sebelum menjadi kader posyandu.

2. Masa Nifas

Masa nifas adalah masa dimulai beberapa jam sesudah lahirnya plasenta sampai 6 minggu setelah melahirkan. (Pusdiknakes,2003)

Periode masa nifas (puerperium) adalah perode waktu selama 6-8 minggu setelah persalinan.proses ini di mulai setelah selesainnya persalinan dan berakhir setelah alat-alat reproduksi kembali keadaan sebelum hamil/ tidak hamil sebagai akibat dari adannya perubahan fisiologis dan fsikologi karena proses persalinan. (Purwati, 2012)

Periode masa nifas di bagi menjadi tiga, yaitu sebagai berikut:

a. Periode immediate postpartum

Masa segera setelah plasenta lahir sampai dengan 24 jam.pada masa ini sering terdapat banyak masalah seperti pendarahan

b. Periode Early postpartum (24 jam-1 minggu)

Masa dimana involsi uterus harus dipastikan dalam keadaan normal,tidak ada pendarahan,lokea tidak berbau busuk,tidak demam,ibu cukup mendapatkan makanan dan cairan,serta ibu dapat menyusui dengan baik

c. Periode Late Postpartum (1-5 minggu)

Masa di mana perawatan dan pemeriksaan kondisi sehari-hari,serta konseling $\mathrm{KB}$

Pembagian masa nifas di bagi dalam tiga periode

a. Peurperium Dini

Kepulihan dimana ibu telah diperbolehkan berdiri dan berjalan-jalan

b. Peurperium intermedial

Kepulihan menyeluruh alat-alat genitalis yang lamanya 6-8 minggu

c. Remote peurperium

Waktu yang diperlukan untuk pulih dan sehat sempurna terutama bila selama hamil atau waktu persalinan mempunyai komplikasi

3. Pijat Nifas

Pijat nifas yang dimaksud adalah pijat pada ibu nifas yang dilakukan dari kepala hingga ke kaki. Pijat ini dalam rangkaian post natal treatment. (WHO,2013)

Kelelahan bagi ibu yang baru saja melahirkan dan mengurus bayi dapat menyebabkan stres. Atasi semua hal tersebut dengan pijat. Manfat dari pijat nifas adalah sebagai berikut;

a. Mengencangkan otot

Selama kehamilan otot-otot tubuh tidak rileks. Sisihkan waktu untuk memijat tubuh agar kembali rileks dan kebugaran tubuh dapat kembali

b. Berat badan

Setelah melahirkan, bagaimana mengembalikan bentuk tubuh seperti semula. Pijat dapat mengecilkan perut dan membakar lemak tubuh.

c. Mengurangi stretch mark

Stretch dapat dikurangi di perut dan kaki dengan memijat secara teratur. Gunakan minyak esensial untuk mengurangi stretch mark. 
d. Pengelupasan kulit

Pijat dapat membantu pengelupasan kulit-kulit mati usai melahirkan. Perempuan yang baru melahirkan, sibuk dengan bayinya sehingga memiliki waktu yang sangat sedikit untuk memperhatikan tubuhnya, bahkan kesehatan kulit.

\section{Metode}

Lakukan pijat untuk mendapat semua manfaat tersebut.

1. Analisis situasi

a. Melakukan kajian/survey awal di lahan untuk mengetahui tingkat kesehatan perempuan. Proses ini melibatkan Kepala Desa, Kepala Puskesmas dan Bidan Desa setempat untuk mendapatkan data awal tentang kesehatan perempuan dan SDM berbasis masyarakat yang bergerak untuk meningkatkan kesehatan perempuan.

b. Melakukan kajian terhadap lahan untuk mengetahui potensi kader posyandu. Data didapatkan 28 kader aktif dan terlibat langsung dalam kegiatan-kegiatan posyandu dan masih terbatas dalam pelayanan rutin, seperti penimbangan bayi balita di posyandu, penyuluhan sederhana tentang manfaat posyandu, pendampingan kasus rujukan dan senam kader bulanan.

2. Perijinan

Melakukan perijinan ke Dinas Kesehatan Kabupaten Bandung, Kesbangpol, Kecamatan dan Kelurahan setempat.

3. Penyusunan Materi

Materi disesuaikan dengan salah satu hasil analisis situasi, bahwa perlu diadakan upaya peningkatan pengetahuan dan kemampuan kader untuk meningkatkan kesejahteraan melalui pelayanan yang diberikan kepada ibu nifas.

4. Implementasi

a. Mengumpulkan kader di aula desa

b. Menyampaikan materi

b.1 Kader dan kewenangannya

b.2 Pengertian ibu nifas

b.3 Kebutuhan ibu nifas

b.4 Pijat Nifas

c. Membagi kelompok

d. Melatih pijat nifas

d.1 Uji pendahuluan

d.2 Pelatihan

Melatih kader dengan menggunakan metode simulasi, bed site teaching dan praktik langsung kepada model (perempuan)

d.3 Post test

d.4 Implementasi

Melakukan praktik langsung pijat nifas kepada model (perempuan)

e. Mengevaluasi proses

e.1 Observasi pelaksanaan pijat nifas 
Jurnal Pengabdian Kepada Masyarakat

e.2 Memberikan masukan untuk meningkatkan kualitas

5. Perumusan laporan kegiatan

6. Publikasi internal dan ekternal

\section{Hasil dan Pembahasan}

Hasil

1. Pengetahuan Kader tentang pijat nifas

Jumlah kader 28 orang dengan distribusi pengetahuan tentang pijat nifas

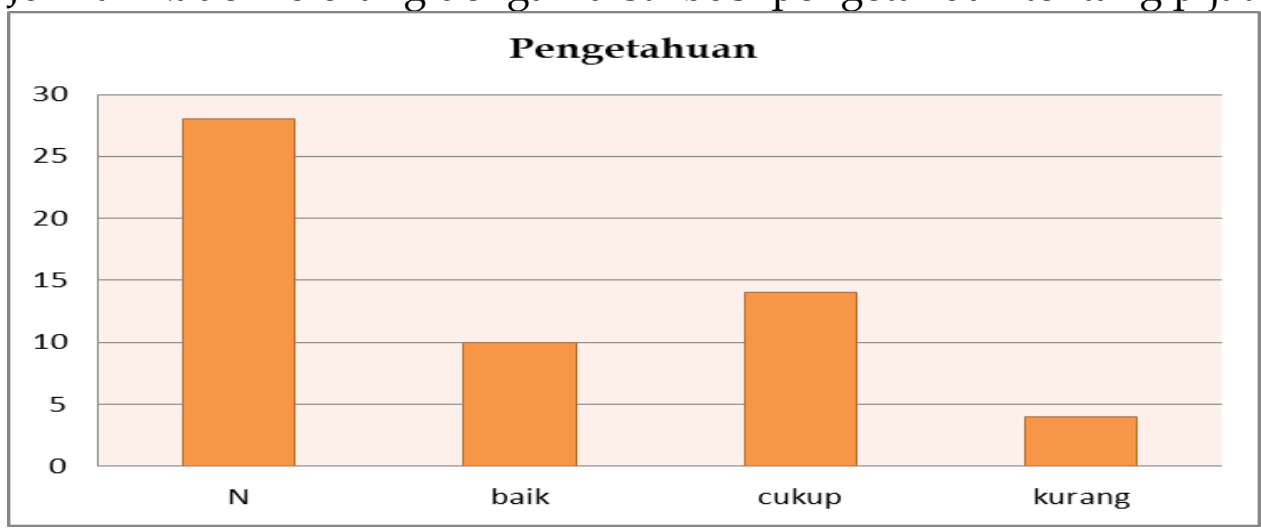

Gambar 1. Pengetahuan Kader tentang pijat nifas

Berdasarkan gambar 1, pengetahuan kader tentang pijat nifas sebagian besar berpengetahuan cukup 14 orang, berpengetahuan baik 10 orang dan sebagian kecil berpengetahuan kurang sejumlah 2 orang.

2. Pemahaman Kader tentang pijat nifas

Jumlah kader 28 orang dengan distribusi pemahaman tentang pijat nifas

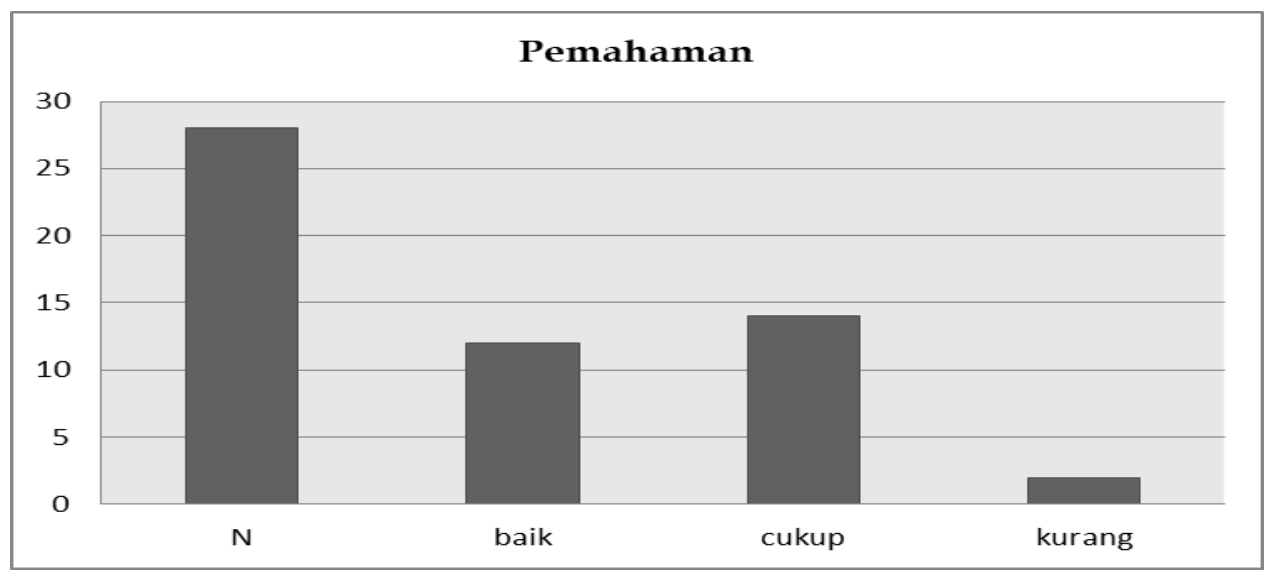

Gambar 2. Pemahaman Kader tentang pijat nifas

Berdasarkan gambar 2, pemahaman kader tentang pijat nifas sebagian besar berpengetahuan cukup 14 orang, berpengetahuan baik 12 orang dan sebagian kecil berpengetahuan kurang sejumlah 2 orang.

3. Kemampuan Kader tentang pijat nifas

Jumlah kader 28 orang dengan distribusi pengetahuan tentang pijat nifas 


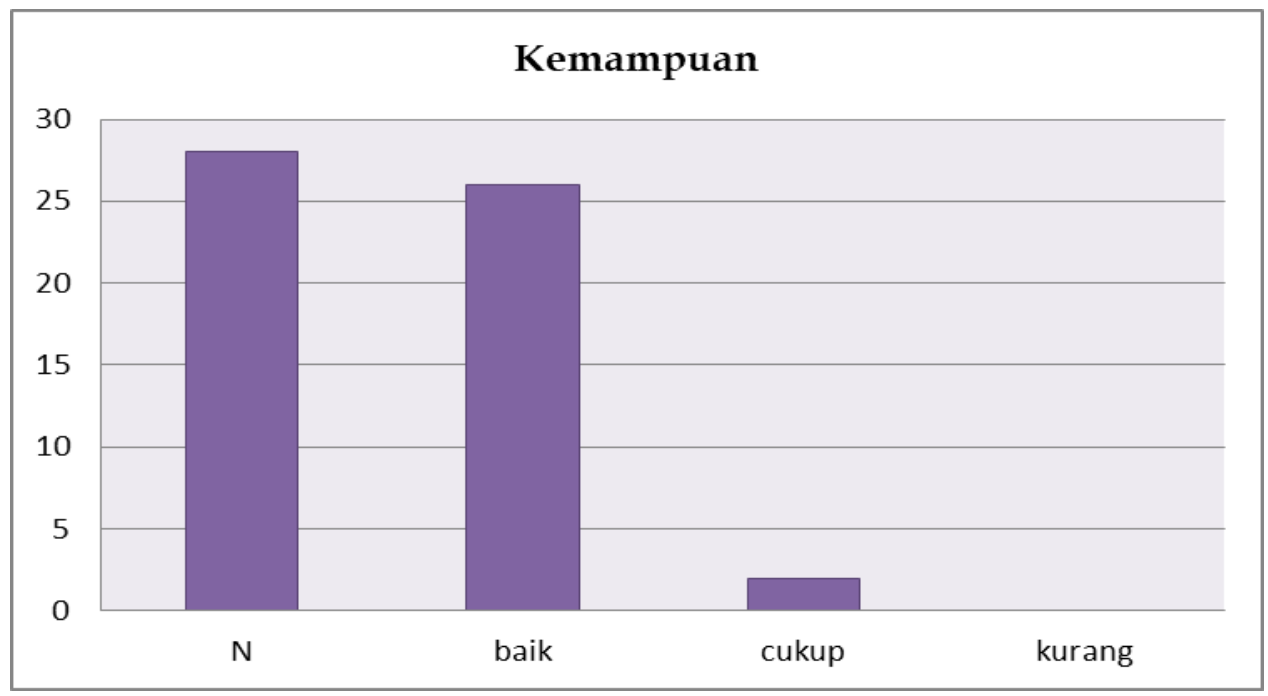

Gambar 3. Kemampan Kader melakukan pijat nifas

Berdasarkan gambar 3, maka kemampuan kader setelah mengikuti pelatihan pijat nifas maka sebagian besar dengan kemampuan baik 26 orang dan dengan kemampuan cukup 2 orang.

\section{Pembahasan}

Sebelum diberikan pelatihan, dilakukan uji pendahuluan lebih dulu untuk mendeskripsikan pengetahuan dan pemahaman kader tentang pijat nifas. Hasil didapatkan bahwa pemahaman kader tentang pijat nifas sebagian besar berpengetahuan cukup 14 orang, berpengetahuan baik 12 orang dan sebagian kecil berpengetahuan kurang sejumlah 2 orang. Pemahaman kader tentang pijat nifas sebagian besar berpengetahuan cukup 14 orang, berpengetahuan baik 12 orang dan sebagian kecil berpengetahuan kurang sejumlah 2 orang. Berdasarkan hasil awal, maka dilakukan penyampaian materi tentang pijat nifas dengan harapan dapat menambah wawasan kader. Proses selanjutnya dilakukan latihan-latihan bagaimana melakukan pijat nifas dengan memperhatikan dan penekanan kapasitas kader bukan sebagai tenaga kesehatan tetapi dapat melakukan pijat nifas dengan memperhatikan hal-hal khusus. Bagian-bagian tertentu seperti perut yang tidak diperlukan pijatan setelah melahirkan. Segera mengambil langkah pendampingan dan rujukan jika terdapat kondisi darurat pada ibu nifas. Materi tambahan bagi kader bahwa manfaat penyerta yang bisa dimanfaatkan bagi kader adalah untuk menambah pemasukan ekonomi.

Evaluasi pelaksanaan dilakukan pada hari selanjutnya untuk memastikan kemampuan kader dalam melakukan pijat nifas. Hasil yang didapatkan bahwa kemampuan kader setelah mengikuti pelatihan pijat nifas sebagian besar dengan kemampuan baik 26 orang dan dengan kemampuan cukup 2 orang. Pendampingan dilakukan secara insentif bagi 2 orang kader dengan nilai cukup untuk memastikan kemampuannya menjadi baik. Sebagai tindak lanjut dari pelatihan ini, maka pelatih berkolaborasi bersama petugas kesehatan dan pemerintahan setempat untuk melakukan pemantauan selanjutnya. Salah satu penelitian yang dilakukan oleh Susanta, menyatakan bahwa peran tenaga kesehatan sebagai fungsi fasilitator 
menjadi salah satu faktor keberhasilan pemberdayaan keluarga dalam meningkatkan kesejahteraan dan kesehatan keluarga. (Susanta, 2017)

\section{Simpulan dan Rekomendasi}

Simpulan yang didapat dalam pemberdayaan perempuan melalui pelatihan pijat nifas bagi kader disimpulkan bahwa sebagian pengetahuan dan pemahaman kader tentang pijat nifas adalah cukup. Kemampuan kader dalam mengimplemetasikan pijat nifas adalah baik. Manfaat penyerta yang bisa dimanfaatkan bagi kader adalah untuk menambah pemasukan ekonomi. Rekomendasi pelatihan ini diperlukan pendampingan dan pemantauan petugas kesehatan dan pemerintah setempat untuk mengembangkan terus potensi kader dalam rangka pemberdayaan perempuan. Pelatihan pijat nifas ini terbatas, sehingga diperlukan pelatihan-pelatihan lanjutan atau topik lainnya untuk memampukan pemberdayaan perempuan.

\section{Acknowledgements}

Diucapkan terimakasih kepada Dinas Kesehatan Kabupaten Bandung, Puskesmas Pakutandang Ciparay Kabupaten Bandung, Camat Ciparay dan Kepala Desa Babakan Kecamatan Ciparay Kabupaten Bandung beserta jajarannya yang telah membantu dalam proses pemberdayaan perempuan dalam pelatihan kader ini. Harapan agar kerjasama dapat dilanjutkan melalui kegiatan pengabdian kepada masyarakat dalam bentuk lainnya.

\section{Daftar Pustaka}

Departemen Kesehatan RI (2006). Pedoman Umum Pengelolaan Posyandu. Direktorat Bina Gizi Masyarakat. Jakarta.

Gomes (2003). Pengertian Pelatihan dalam Manajemen Sumberdaya Manusia

Kartasasmita Ginanjar. (1996)Pembangunan untuk Rakyat Memadukan Pertum buhan dan Pemerataan. PT. Pustaka Cidesindo ; Jakarta

Pusdiknakes (2003). Asuhan Kebidanan Postpartum. Jakarta

Purwati, Eni (2012). Asuhan Kebidanan Untuk Ibu Nifas. Yogyakarta. Cakrawala Ilmu.

Rahayu, Y S. Mahanka,R. Aisyah,I. (2018). Pemberdayaan Ekonomi Keluarga Melalui Kelompok PKK Rw 10 Kel.Babakan Sari Bandung : JurnaL ABDIMAS BSI Vol. 1 No. 1 Februari 2018, Hal. 149-154

Susanta. (2017). Peran Pendamping Dalam Program Keluarga Harapan (PKH) Di Puskesmas Bayat Kabupaten Klaten. 
Jurnal Pengabdian Kepada Masyarakat

Tania, M. Suryani. Hernawaty,T. (2019). Pengalaman Hidup Kader Kesehatan dalam Mendukung Proses Recovery di Melong Kota Cimahi : Jurnal Keperawatan BSI, Vol. VII No. 1 April 2019 ISSN: 2338-2746, e-ISSN: 2528-2239 100

WHO (2013). Postnatal Care for Mothers and Newborns. Highlights from the WHO Guidelines.

Zulkifli (2003). Posyandu dan Kader Kesehatan. FKM-USU 